BUDGETING : Journal of Business, Management and Accounting

Volume 2, Nomor 1, Desember 2020

e-ISSN: 2715-2480

p-ISSN: 2715-1913

DOI : https://doi.org/10.31539/budgeting.v2i1.1237

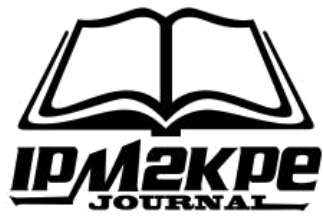

\title{
ESKALASI KOMITMEN BERDASARKAN INFORMASI INVESTASI, KONDISI ADVERSE SELECTION DAN JOB ROTATION
}

\author{
Vinando Bintang ${ }^{1}$, Arik Susbiyani ${ }^{2}$, Achmad Syahfrudin ${ }^{3}$ \\ Universitas Muhammadiyah Jember ${ }^{1,2,3}$ \\ vinando2020@gmail.com ${ }^{1}$
}

\begin{abstract}
ABSTRAK
Tujuan penelitian ini adalah untuk mengetahui pengaruh informasi investasi, kondisi pemilihan adverse selection dan job rotation terhadap eskalasi komitmen. Metode penelitian ini menggunakan metode kuantitatif. Penelitian ini menggunakan desain faktorial $2 \times 2$. Data yang dikumpulkan dalam penelitian ini merupakan data primer yang diperoleh dengan pemberian kuesioner berupa studi kasus. Hasil penelitian menunjukkan bahwa analisis informasi investasi memperoleh nilai uji $<0,05$. Hasil yang sama juga diperoleh pada analisis interaksi antara adverse selection dan job rotation. Simpulan, informasi investasi (investasi negatif dan investasi positif) dan interaksi antara adverse selection dan job rotation mampu mempengaruhi keputusan manajer untuk melakukan eskalasi.
\end{abstract}

Kata Kunci: Adverse Selection, Eskalasi Komitmen, Informasi Investasi, Job Rotation

\section{ABSTRACT}

The purpose of this study was to determine the effect of investment information, adverse selection conditions and job rotation on the escalation of commitment. This research method using quantitative method. This study used a $2 \times 2$ factorial design. The data collected in this study are primary data obtained by giving a questionnaire in the form of a case study. The results showed that the analysis of investment information obtained a test value $<0.05$. The same results were obtained in the interaction analysis between adverse selection and job rotation. In conclusion, investment information (negative investment and positive investment) and the interaction between adverse selection and job rotation are able to influence manager's decisions to escalate.

Keywords: Adverse Selection, Commitment Escalation, Investment Information, Job Rotation

\section{PENDAHULUAN}

Peran manajer sangatlah penting bagi perusahaan karena setiap keputusan yang diambil manajer sangatlah berpengaruh. Namun, dengan banyaknya pertimbangan dapat membuat manajer menjadi bingung akan keputusan yang akan diambil. Manajer cenderung lebih meningkatkan komitmennya ketika akan mengambil keputusan yang menurutnya tepat. Karena adanya motivasi keinginan pribadi, terkadang seorang 
manajer mengambil keputusan yang bertentangan dengan pemilik perusahaan. Pengambilan keputusan merupakan bagian fluktuatif dari keberhasilan atau kegagalan seorang manajer (Sahmuddin, 2003). Ada beberapa faktor yang mempengaruhi eskalasi komitmen antara lain informasi investasi, adverse selection dan job rotation.

Menurut Tanjung (2012) pengambilan keputusan berlaku dalam kehidupan sehari-hari maupun dalam dunia bisnis. Dalam mengambil sebuah keputusan, manajer perlu memantau perkembangan investasi yang masuk agar manajer dapat memutuskan apakah proyek yang sedang berjalan akan tetap lanjut atau berhenti. Informasi investasi harus disajikan dengan data yang kongkrit dan kredibel agar bisa mengidentifikasi apakah investasi yang masuk dapat diolah secepatnya sehingga masa depan sebuah proyek dapat terlihat. Informasi investasi yang disajikan bisa berbentuk positif (untung) atau negatif (rugi).

Hasil penelitian Rutledge \& Karim (1999) menunjukkan bahwa manajer yang mengalami adverse selection akan melakukan eskalasi komitmen. Jensen \& Meckling (1976) mengungkapkan bahwa adverse selection merupakan suatu kondisi dimana terdapat asimetri informasi antara pihak principal dengan pihak agen. Hal tersebut didukung Scott (2000) yang menyatakan bahwa dalam kondisi adverse selection, manajer mengetahui lebih banyak tentang keadaan dan prospek perusahaan dibanding principal. Fakta-fakta yang mungkin mempengaruhi keputusan principal tersebut tidak disampaikan informasinya. Menurut Harrel \& Harrison (1994) ketika kepentingan manajer saling bertentangan dengan pemilik perusahaan, manajer memiliki celah untuk mengelak. Manajer berpeluang untuk membuat keputusan yang tidak sesuai dengan kepentingan pemilik.

Hal lain yang dapat membuat seseorang melakukan eskalasi komitmen adalah tidak diterapkannya job rotation. Job rotation didefinisikan sebagai perpindahan tugas secara lateral bagi para karyawan dalam suatu organisasi dengan berbagai variasi interval waktu, seperti lima tahun atau lebih yang berlaku untuk semua jenis karyawan sepanjang karir mereka, dimana tidak termasuk promosi (Chong \& Surwayati, 2007). Job rotation terjadi pada semua jabatan yang sekiranya jabatan tersebut sudah diduduki selama bertahun-tahun. Hal ini membuat setiap orang bisa mendapatkan pengalaman yang lain serta tanggung jawab. 
Kebijakan job rotation memerlukan kerjasama antara on going employee dengan incoming new employee terutama pada masa transisi. Seorang manajer yang tengah menangani sebuah proyek perlu bekerja sama dengan calon penggantinya dalam hal memberikan laporan yang komprehensif mengenai performa proyek tersebut.

Pengambilan keputusan manajer untuk melanjutkan proyek dapat dilihat berdasarkan informasi mengenai proyek yang sedang dijalankan. Informasi proyek yang dijalankan dapat disajikan informasi positif (untung) dan informasi negatif (rugi). Menurut Kelly \& Milkman (2011) dalam eskalasi komitmen, pembuat keputusan melihat pada setiap risiko, dimana harus adanya komitmen untuk menerima hasil yang diharapkan (positif) maupun hasil yang mengecewakan (negatif). Hasil keputusan dapat dibingkai dengan keuntungan dan kerugian, tergantung pada referensi titik yang dipilih. Setiap manajer mempunyai gaya tersendiri dalam pengambilan keputusan. Informasi yang diperoleh dapat dibuat sebagai pedoman dalam pengambilan keputusan karena disana terdapat rincian informasi terhadap proyek yang sedang dilakukan. Informasi merupakan satu sumber daya yang sangat diperlukan dalam suatu organisasi dengan adanya data yang telah diolah menjadi bentuk yang lebih berguna dan lebih berarti bagi yang menerimanya untuk pengambilan keputusan (Zakiyudin, 2012).

\section{KAJIAN TEORI}

\section{Teori Keagenan (Agency Theory)}

Teori agensi didasarkan pada pandangan bahwa perusahaan sebagai sekumpulan kontrak diantara faktor-faktor produksi dan hubungan diantara prinsipal dan agen. Teori keagenan menjelaskan bahwa dalam perusahaan terdapat punumpukan kontrak, di satu pihak (principal) mendelegasikan tugas kepada pihak lain yaitu agen untuk menyelesaikan tugas tersebut (Jansen \& Meckling, 1976). Teori agensi terjadi apabila ada kepentingan tersendiri antara prinsipal dengan agen.

Agen diberi wewenang untuk mengambil keputusan demi memajukan perusahaan tetapi si agen mempunyai informasi privat yang tidak diketahui principal sehingga terjadi asimetri informasi antara principal dengan agen. Hal ini akan mengacu konflik antara agen dengan principal atas dasar keputusan manajer yang tidak wajar. Namun kepentingan agen bisa saja berjalan dengan perusahaan ataupun malah bertentangan. 


\section{Teori Prospek (Prospect Theory)}

Gudono \& Hartadi (1998) menyebutkan bahwa dominasi teori ini nampak jelas dalam pembahasan tentang pembuatan keputusan pada kondisi ketidakpastian yang terdapat dalam berbagai literatur akuntansi manajemen, manajemen keuangan, dan ekonomi manajerial. Hal ini membuat individu akan bersifat menghindari risiko atau menyukai risiko tergantung pada kondisi yang dihadapi. Dalam praktek seringkali ditemui penyimpangan dari asas rasionalitas.

Manajer seringkali meneruskan proyek yang mengalami kerugian terus menerus meskipun secara ekonomis proyek itu seharusnya dihentikan (Sahmuddin, 2003). Teori prospek digunakam untuk melihat pengaruh sunk cost yang meningkat terus menerus dalam pelaksanaan suatu proyek, tetapi manajer mempunyai perilaku yang tidak ingin berhenti dalam proyek tersebut (Eveline, 2010). Karena sunk cost menjadi tolak ukur pertimbangan terhadap nama baik atas tanggung jawab suatu proyek, maka hal tersebut dapat mengakibatkan manajer menghadapi masalah eskalasi komitmen.

\section{Informasi Investasi}

Informasi yang diperoleh dapat dijadikan pedoman dalam pengambilan keputusan untuk memunculkan pilihan-pilihan keputusan yang akan dipilih. Pentingnya informasi investasi menjadi pertimbangan penting dalam perusahaan, karena perusahaan memerlukan sumber dana alternatif untuk menjalankan proyek. Menurut Zakiyudin (2012) informasi merupakan satu sumber daya yang sangat diperlukan dalam suatu organisasi dengan adanya data yang telah diolah menjadi bentuk yang lebih berguna dan lebih berarti bagi yang menerimanya untuk pengambilan keputusan. Informasi investasi yang disajikan haruslah relevan, tepat waktu, akurat dan konsisten agar pengambilan keputusan bisa diambil secara tepat.

Informasi investasi akan dipakai untuk pengambilan keputusan oleh manajer karena di dalamnya terdapat informasi dana yang tersedia sehingga bisa mengetahui keadaan proyek kedepan bisa dilanjutkan atau tidak. Pengukuran kinerja keuangan meliputi hasil perhitungan rasio-rasio keuangan yang berbasis pada laporan keuangan perusahaan yang dipublikasikan dan telah diaudit oleh akuntan publik. Perhitungan rasio tersebutlah yang nantinya akan menjadi cerminan bagi para manajer untuk 
mengetahui apakah nilai perusahaan berada dalam kondisi yang lebih baik atau sebaliknya (Wiagustini, 2010).

\section{Adverse Selection}

Informasi antara manajer dengan perusahaan sangatlah diperlukan untuk menjalankan suatu proyek kedepan. Namun informasi yang didapat manajer tidak selalu disampaikan semuanya ke principal karena manajer mempunyai targetnya dalam tanggung jawab serta menaikkan citranya dengan cara memberikan keuntungan dan kepuasan kinerjanya ke perusahaan. Tetapi bila manajer mempunyai kepentingan pribadi, manajer cenderung mengungkapkan semua informasi yang didapat ke principal dan kemudian mengabaikannya.

Menurut Salter \& Sharp (1997) seorang manajer akan mengejar kepentingan sendiri apabila ada dua hal, yaitu: 1) insentif untuk mengelak, yaitu hadiah bagi manajer untuk melanjutkan proyek (meningkat) lebih tinggi daripada menghentikannya; 2) asimetri informasi, yaitu adanya informasi yang menurut manajer sangat penting (bersifat menguntungkan pribadi) yang tidak disampaikan ke principal. Hal tersebut didukung oleh Yusnaini (2005) bahwa ada dua kondisi yang membuat manajer berperilaku mengabaikan kepentingan perusahaan yaitu motivasi manajer dalam melakukan tindak kecurangan dan terjadinya asimetri informasi. Apabila informasi yang didapat manajer sama dengan pemilik, maka manajer tidak mempunyai kesempatan untuk melalaikan tugasnya.

\section{Job Rotation}

Job rotation merupakan salah satu alternatif untuk menghindari eskalasi komitmen. Eguchi (2005) menemukan bahwa transfer karyawan diantara berbagai pekerjaan dalam perusahaan dapat mencegah karyawan dari performa yang melibatkan aktivitas untuk kepentingan pribadi. Namun job rotation mempunyai kelemahan yaitu biaya pelatihan akan meningkat, anggota perusahaan menjadi terganggu dengan penyesuaian diri dan produktivitasnya berkurang.

Perusahaan mempunyai tujuan dalam menerapkan job rotation, masing-masing diantaranya yaitu memaksimalkan produktivitas karyawan, menyeimbangkan komposisi 
terkait keahlian dan memaksimalkan pengalaman serta pengetahuan pekerja (Chong \& Surwayati, 2007).

\section{Eskalasi Komitmen}

Seorang manajer sering menjadi dilematis karena keputusan yang akan diambil. Hal ini dikarenakan keputusan tersebut akan berpengaruh terhadap perusahaan. Dengan demikian, seorang manajer tidak boleh sembarangan dalam mengambil keputusannya. Semua harus dipertimbangkan agar keputusan yang diambil menjadi pilihan yang menurutnya tepat. Eskalasi komitmen dapat dikatakan sebagai upaya meningkatkan keseriusan atau keloyalan terhadap komitmen yang telah dibuat, karena dengan semakin kuatnya komitmen seorang individu, maka diharapkan loyalitas terhadap perusahaan dan pekerjaannya juga semakin meningkat (Loekman, 2012).

Komitmen yang dimaksud ditekankan pada tingkat keterikatan individu terhadap suatu proyek. Eskalasi komitmen pada umumnya dilakukan oleh para pengambil keputusan dimana dalam hal ini pengambil keputusan yang dimaksud adalah seorang manajer perusahaan. Walaupun terkadang keputusan yang diambil berisiko bagi perusahaan karena berupaya agar proyek dapat terlaksanakan sesuai dengan rencana, terkadang manajer berpotensi melakukan eskalasi komitmen karena tergiur akan keuntungan yang akan diterimanya.

\section{METODE PENELITIAN}

Penelitian ini menggunakan metode kuantitatif dengan menyiapkan instrument berupa kasus pembuatan keputusan. Faktor-faktornya terdiri dari atas 3 variabel dependen, yaitu informasi investasi, adverse selection dan job rotation. Adapun variabel independen yaitu eskalasi komitmen. Perlakuan manipulasi atas informasi investasi yang disajikan dengan perlakuan dapat berupa informasi negatif dan informasi positif. Perlakuan A diberikan studi kasus informasi investasi positif. Perlakuan B diberikan studi kasus informasi investasi negatif. Selanjutnya penelitian job rotation dan adverse selection dijabarkan dengan desain eksperimen factorial $2 \times 2$. 
Tabel 1.

Desain penelitian eksperimen factorial $2 \times 2$

\begin{tabular}{cccc}
\hline \multirow{2}{*}{ Perlakuan / Perlakuan } & \multicolumn{2}{c}{ Adverse Selection } \\
\cline { 3 - 4 } & Ada & Ada & Tanpa \\
\hline Job Rotation & Tanpa & Perlakuan C & Perlakuan E \\
\hline
\end{tabular}

Dalam penelitian ini, data yang dikumpulkan adalah data primer dengan memberikan kuisioner dalam bentuk berupa studi kasus. Teknik survei yang dilakukan ini adalah dengan cara memberikan kuisioner yang berisi studi kasus kepada responden lalu hasil jawaban dikumpulkan lagi ke peneliti. Kemudian hal tersebut dinamakan sebagai data primer.

Responden yang dilibatkan dalam penelitian ini adalah mahasiswa Universitas Muhammadiyah Jember Fakultas Ekonomi Prodi Akuntansi yang sudah menempuh mata kuliah Akuntansi Manajemen dan Akuntansi Keprilakuan. Dalam pengambilan populasi dan sampel dalam penelitian ini menggunakan penelitian kuarsa eksperimen, yaitu objek yang diambil berdasarkan keinginan peneliti. Hal tersebut dilakukan karena dapat menunjang peneliti untuk mengefisiensi waktu dan biaya selama penelitian.

Variabel independen adalah variabel yang sering disebut sebagai variabel stimulus dan variabel bebas. Variabel ini mempengaruhi atau yang menjadi sebab perubahan atau timbulnya variabel dependen. Variabel yang menjelaskan dan mempengaruhi variabel lain dalam penelitian ini, yaitu: $X_{1}=$ informasi investasi; skala pengukuran variabel informasi investasi (informasi investasi negatif $=1$ dan informasi investasi positif $=2) ; \mathrm{X}_{2 \mathrm{a}}=$ adverse selection; $\mathrm{X}_{2 \mathrm{~b}}=$ job rotation; skala pengukuran (kondisi job rotation pada kondisi adverse selection $=1$; kondisi tanpa job rotation pada kondisi adverse selection $=2$; kondisi job rotation pada kondisi tanpa adverse selection $=3$; kondisi tanpa job rotation pada kondisi tanpa adverse selection $=4$.

Variabel dependen atau sering disebut variabel terikat merupakan variabel yang dipengaruhi atau yang menjadi akibat karena adanya variabel bebas. Variabel dependen dalam penelitian ini yaitu: $\mathrm{Y}=$ eskalasi komitmen; skala pengukuran (eskalasi komitmen: skala likert 1-6). 


\section{HASIL PENELITIAN}

Hasil pengujian untuk mengukur pengaruh informasi investasi terhadap eskalasi komitmen dalam melanjutkan proyek yang mengindikasikan kegagalan menunjukkan pengaruh yang signifikan yaitu sebesar 0,000 ( $\mathrm{p} \leq 0,05)$. Adapun pengujian untuk mengukur pengaruh interaksi antara job rotation dengan kondisi adverse selection terhadap keputusan untuk melakukan eskalasi komitmen oleh manajer juga menunjukkan hasil yang signifikan yaitu sebesar $0,008(\mathrm{p} \leq 0,05)$.

Berdasarkan hasil pengujian statistic di atas, dapat dilihat dengan jelas bahwa semua variabel independen berpengaruh terhadap variabel dependen. Variabel-variabel independen tersebut berpengaruh secara positif, artinya manajer lebih memilih melanjutkan proyek walaupun proyek tersebut telah mengindikasikan kegagalan.

\section{PEMBAHASAN}

Eskalasi komitmen merupakan tendensi dari pengambil keputusan untuk tetap bertahan atau mengeskalasi komitmennya pada serangkaian tindakan yang gagal. Bazerman (1994) mendefinisikan eskalasi sebagai derajat dimana individu mengeskalasikan komitmen untuk tindakan-tindakan tertentu yang dilakukan sebelumnya sampai kepada satu titik yang melewati model pengambilan keputusan yang rasional. Adapun menurut Santoso (2012), eskalasi komitmen diartikan sebagai fenomena yang menjelaskan bahwa seseorang memutuskan untuk meningkatkan atau menambah investasinya, walaupun bukti baru menjelaskan bahwa keputusan yang telah dilakukan adalah salah. Dengan kata lain bahwa eskalasi komitmen merupakan tindakan meningkatkan atau memperluas suatu komitmen awal terhadap suatu proyek atau investasi tertentu meskipun proyek atau investasi tersebut telah memberikan umpan balik negatif atau tidak menguntungkan (Tanjung, 2012).

Pengambilan keputusan adalah suatu proses penetapan pilihan dari berbagai alternatif cara bertindak dengan metode yang efisien sesuai dengan situasi. Seseorang seringkali dihadapkan dengan berbagai alternatif pilihan dalam hidupnya yang menuntutnya untuk mengambil suatu keputusan. Menurut Soenhadji (2010) seorang pengambil keputusan harus memperhatikan hal-hal seperti logika, realita, rasional dan pragmatis. 


\section{Informasi Investasi}

Informasi investasi disajikan dalam dua kondisi yaitu posisi untung dan posisi rugi. Informasi yang disajikan dalam posisi menguntungkan cenderung membuat individu berhati-hati untuk setiap pengambilan keputusan. Sedangkan informasi yang disajikan dalam posisi tidak menguntungkan cenderung menunjukkan individu lebih menyukai risiko agar mendapat pengembalian di masa mendatang. Manajer akan memandang keputusan selanjutnya sebagai pilihan keputusan antara kerugian yang pasti terjadi dengan tidak menambah investasi atau kerugian dimasa mendatang yang kurang pasti dengan risiko menambah dana dan berharap mendapat pengembalian positif (Edfa \& Dwita, 2019).

Berdasarkan hasil penelitian, informasi investasi yang disajikan dalam informasi investasi negatif dan informasi investasi positif ternyata mampu mempengaruhi pengambil keputusan (manajer) untuk melakukan eskalasi terhadap komitmennya yang dalam hal ini diukur dengan pertimbangan untuk melanjutkan proyek yang mengindikasikan kegagalan. Hasil penelitian ini sedikit berbeda dengan hasil penelitian Soma \& Lestari (2017) yang menunjukkan bahwa informasi investasi negatif tidak berpengaruh secara signifikan terhadap keputusan manajer untuk melakukan eskalasi komitmen.

\section{Kondisi Adverse Selection dan Job Rotation}

Nurhayati \& Sukirno (2014) menyatakan bahwa adverse selection terbukti berpengaruh terhadap eskalasi komitmen. Demikian pula dengan job rotation yang dapat berpengaruh dalam memaksimalkan produktivitas karyawan, menyeimbangkan komposisi terkait keahlian dan memaksimalkan pengalaman serta pengetahuan pekerja (Chong \& Surwayati, 2007).

Hasil analisis data membuktikan bahwa interaksi antara job rotation dengan adverse selection berpengaruh terhadap keputusan untuk melakukan eskalasi komitmen. Temuan ini sesuai dengan hasil yang diperoleh pada penelitian Dewanti (2010) yang menyebutkan bahwa terdapat pengaruh interaksi antara job rotation dengan adverse selection terhadap keputusan untuk melakukan eskalasi komitmen. Namun Chong \& Surwayati (2007) menyebutkan bahwa ketika manajer memiliki informasi privat, 
kebijakan job rotation secara signifikan mengurangi dampak informasi privat pada perilaku eskalasi.

\section{SIMPULAN}

Informasi investasi yang disajikan dalam informasi investasi negatif dan informasi investasi positif mampu mempengaruhi pengambil keputusan (manajer) untuk melakukan eskalasi terhadap komitmennya yang dalam hal ini diukur dengan pertimbangan untuk melanjutkan proyek yang diindikasikan mengalami kegagalan. Adapun hasil uji interaksi job rotation dan adverse selection menunjukkan bahwa variabel tersebut mampu mempengaruhi keputusan manajer untuk melakukan eskalasi komitmen.

\section{DAFTAR PUSTAKA}

Bazerman, M. H. (1994). Judgment in Managerial Decision Making, 3rd Ed. New York: Wiley

Chong, C., \& Surwayati, S. (2007). De-Escalation Strategis: The Impact of Job Rotation and Monitoring Control on Manager's Project Evaluation Decisions. Diakses dari http://www.papers.ssrn.com

Dewanti, R. (2010). Pengaruh Negative Framing dan Job Rotation pada Kondisi Adverse Selection terhadap Pengambilan Keputusan Eskalasi Komitmen. Skripsi. Universitas Diponegoro

Edfa, A. R., \& Dwita, S. (2019). Pengaruh Informasi Investasi dan Overconfidence terhadap Eskalasi Komitmen. Jurnal Eksplorasi Akuntansi, 1(4), 1916-1932

Eguchi, K. (2005). Job Transfer and Influence Activities. Journal of Economic Behavior and Organization, 56(1), 187-197

Eveline, F. (2010). Pengaruh Adverse Selection, Pembingkaian Negatif dan Self Efficacy terhadap Eskalasi Komitmen Proyek Investasi yang tidak Menguntungkan. Jurnal Akuntansi dan Manajemen, 21(2):77-94

Gudono, G., \& Hartadi, H. (1998). Apakah Teori Prospek Tepat untuk Kasus Indonesia?: Sebuah Replikasi Penelitian Tversky dan Kahneman. Jurnal Riset Akuntansi Indonesia, 1(1): 29-42

Harrel, A., \& Harrison, P. (1994). An Insentive to Shirk, Privately Held Information, and Manager's Project Evaluation Decisions. Accounting Organizations and Society, 19(7), 569-577

Jensen, M. C., \& Meckling, W. H. (1976). Theory of the Firm: Managerial Behavior, Agency Costs and Ownership Structure. Journal of Financial Economics, 3(1), 305-360 
Kelly, T. F., \& Milkman, K. L. (2011). Escalation of Commitment. Diakses dari https://faculty.wharton.upenn.edu/wpcontent/uploads/2013/09/2011_10_23_escalation_draft_FINAL_3.pdf

Loekman, A. (2012). Peranan Locus of Control dan Justice terhadap Eskalasi Komitmen dalam Pengambilan Keputusan Penganggaran Modal. Berkala Ilmiah Mahasiswa Akuntansi, 1(2), 20-24

Nurhayati, F., \& Sukirno, S. (2014). Pengaruh Adverse Selection dan Kompensasi terhadap Eskalasi Komitmen. Jurnal Profita: Kajian Ilmu Akuntansi, 2(4), 83-91

Rutledge, R. W., \& Karim, K. E. (1999). The Influence of SelfInterest and Ethical Considerations on Manager's Evaluation Judgements. Accounting, Organizations and Society, 24(1), 173-184

Sahmuddin, S. (2003). Framing, Tanggung Jawab dan Pengalaman dalam Pembuatan Keputusan Pemberian Kredit. Tesis Tidak Dipublikasikan. Universitas Diponegoro

Santoso, A. B. (2012). Peranan Locus of Control, Self-Set dan Organizational-Set Hurdle Rates terhadap Eskalasi Komitmen pada Level Pengambilan Keputusan Penganggaran Modal. Jurnal Ilmiah Mahasiswa Akuntansi, 1(3), 34-39

Scott, W. R. (2000). Financial Accounting Theory, Second Edition. Canada: Prentice Hall

Sharp, D. J., \& Salter, S. B. (1997). Project Escalation and Sunk Costs: A Test of the International Generalizability of Agency and Prospect Theories. Journal of International Business Studies, 28(1), 101-122

Soenhadji, I. M. (2010). Teori Pengambilan Keputusan. Diakses dari https://www.slideserve.com/elyse/pi-jurusan-manajemen-fakultas-ekonomiuniversitas-gunadarma

Soma, A. A., \& Lestari, M. M. D. (2017). Pengaruh Informasi Investasi, Job Rotation dan Kondisi Adverse Selection terhadap Eskalasi Komitmen. Simposium Nasional Akuntansi XX. Jember

Tanjung, A. H. (2012). Akuntansi Pemerintahan Daerah Berbasis Akrual, Pendekatan Teknis Sesuai PP No.71/2011. Bandung: Alfabeta

Wiagustini, N. L. P. (2010). Dasar-Dasar Manajemen Keuangan. Denpasar: Udayana University Press

Yusnaini, Y. (2005). Analisis Framing dan Causal Cognitive Mapping dalam Pengambilan Keputusan Strategik: Suatu Studi Eksperimental. Simposium Nasional Akuntansi VIII. Solo

Zakiyudin, A. (2012). Sistem Informasi Manajemen, Edisi 2. Jakarta: Mira Wacana 